\title{
Mitigation through seepage reduction in dams
}

\author{
Novy Haryati, 1,*, and Abdul Hakam² \\ ${ }^{1}$ Masters Program in Civil Engineering, Faculty of Engineering, Andalas University, Padang, Indonesia \\ ${ }^{2}$ Civil Engineering, Faculty of Engineering, Andalas University, Padang,, Indonesia
}

\begin{abstract}
There are many landslide and damages have occurred at dams due to the seepage. In addition, dam works often took inattention of the underneath soil parameters. This careless works resulted in failure of the dam structure as well as landslides. Based on this reason, a good research to be applied to dams is needed. Further, the potential landslides can be avoided. In this study an analysis of seepage analysis at the bottom of the dam is carried out. The landslide analysis is done by varying the parameter to build up the seepage. The case studies analyzed is taken at the seepage that occurred in Sei Wampu Dam located in North Sumatra. Soil data are obtained from the field tests which have been carried out in the previous work. The numerical simulation using the finite element method is gained to conduct the analysis. During the analyses, the variation of parameters obtained from the seepage calculation was recorded. The obtained seepage parameters that affect the stability of dams are then elaborated. The study results can be used for the mitigation efforts at the dams that have the potential for landslides.
\end{abstract}

\section{Introduction}

Dam is a high wall of concrete to retain water that is erected across a river and may also be used to increase the flow of water for power generation.

Dams require heavy engineering construction which can potentially be hazardous and the resulting structures, if poorly executed, liable to physical damage and malfunction during dam construction, post-construction or utilization period of the dam. [1]

One possible significant failure is landslides that occur due to seepage. A dam creates a large difference in water level between upstream and downstream resulting in pressures that may result in a flow of water in the soil due to water infiltration around the structure. This flow carries fine particles resulting in underground erosion (piping). This erosion will form a seepage lane (flow network) between upstream and downstream and transported fine grains will drift towards rough ground. [2]

Diyala dam located in the city of Baghdad is one dam that needed repairs because of seepage. The dam was built from 1966 to 1969 . From the observations made on the field, it was found that damage to some parts of the dam structure, scouring and piping had occurred. Analysis using the Geoslope-SEEP / W program ver.5 successfully demonstrated that seepage had occurred at the dam foundation. [3]

Seepage from the Golden Gol dams in Pakistan was analyzed by using Geoslope-SEEP / W to model the dam and the foundations. The analysis showed that installation of a $30 \mathrm{~m}$ upstream blanket or a combination of downstream and upstream blankets $(10 \mathrm{~m}$ each) resulted in a similar reduction in the amount of seepage. However, more gradients for blankets are found on the safe side, the construction costs are estimated to be lower than the cutoff costs. [4]

Seepage also occurs from earth dams. By using the Geo-Slope 8 program the isoparametric element node was used to model the Iraqi Al-Adhaim dam and its foundation. This dam has a $3.1 \mathrm{~km}$ embankment zone. The modeling indicated that a clay core significantly reduced the hydraulic exit gradient. [5]

Sei Wampu Dam in North Sumatra Province is $5 \mathrm{~km}$ upstream from the city of Stabat, the capital of Langkat Regency. It is being built to optimize the Irrigation Areas (D.I.) of Secanggang, Hinai, and Wampu and has the potential to provide irrigation for an area of 10,991 Ha. It stores rainwater for lowlands and semi-irrigated rice fields to regulate and optimize agricultural water use by the community, both in the rainy season and in the dry season. The construction of the Sei Wampu Dam began on 4 December 2015 and is planned to be completed in September 2019 (still ongoing).

This study explores the impact of the construction of a dam on Stabat as, along with considerable benefits, this project carries the risks associated with heavy construction including the risk of dam failure. It also examines the efforts made to anticipate failure and mitigation systems in place.

\section{Methodology}

\subsection{Location}

The Sei Wampu Dam is located $\pm 5 \mathrm{~km}$ upstream of the Stabat, the capital of Langkat Regency ( 344 '45.80 "N and 98 24" 09.99 "E).

\footnotetext{
* Corresponding author: novy.haryati@gmail.com
} 


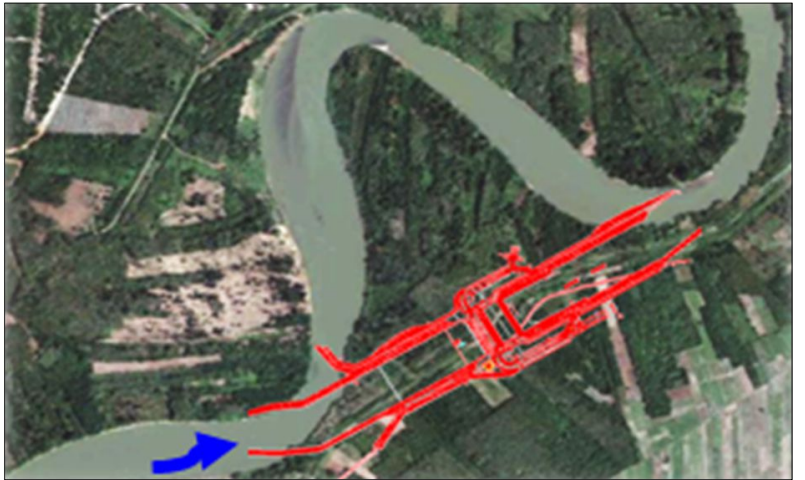

Fig. 1. Sei Wampu Dam Location

\subsection{Soil Investigation}

The scope of work carried out to obtain soil parameter data included:

1. Ten $22 \mathrm{~m}$ to $35 \mathrm{~m}$ bores were made to classify the soil. Eight samples were taken from the land and 2 from the river.

2. A standard penetration test (SPT) was used to determine the parameter $\mathrm{N}$, an indicator of bearing capacity. This was recorded in the boring log.

3. Undisturbed soil samples (UDS) were collected maintaining the soil structure and physical composition in its original condition for laboratory testing. The laboratory tests were:

a. Specific gravity $\left(G_{s}\right)$, including $\gamma_{m}$ and $\gamma_{d}$

b. Water content $(w)$

c. Filter analysis

d. Atterberg limit, to obtain $L L, P L$, and $I P$ values

e. Triaxial test, to obtained $c$ and $\phi$

f. Consolidation test to obtained $C c$

g. Permeability Test to obtain the coefficient $k$.

\subsection{Technical Data}

Pillar of Dam

Pillar width

Pillar height

Length of pillar

Bottom length of pillar

Pillar height from the top floor upstream

$\begin{array}{lll}= & 2 & \mathrm{~m} \\ = & 10 & \mathrm{~m} \\ = & 13,57 & \mathrm{~m} \\ = & 20 & \mathrm{~m} \\ = & 12 & \mathrm{~m}\end{array}$

\section{Upper floor}

Floor width

Floor length

Floor thickness

$\begin{array}{ll}=118,4 & \mathrm{~m} \\ =30 & \mathrm{~m} \\ =1 & \mathrm{~m}\end{array}$

\section{Downstream Floor}

Floor width

Floor length

Floor thickness
Pile Foundation

$\begin{array}{llll}\text { Dam body } & \begin{array}{l}\text { Pile diameter } \\ \text { Number of piles }\end{array} & =50 & \mathrm{~cm} \\ & & & \text { points } \\ \text { Upstream wall } & \begin{array}{l}\text { Pile diameter } \\ \text { Number of piles }\end{array} & =50 & \mathrm{~cm} \\ & & & \text { points } \\ \text { Downstream } & \begin{array}{l}\text { Pile diameter } \\ \text { Number of piles }\end{array} & =50 & \mathrm{~cm} \\ \text { wall } & \text { Nut } & \text { points }\end{array}$

\subsection{Seepage Theory}

\subsubsection{Darcy Theory}

Darcy's law states that magnitude of the flow of a liquid is directly proportional to the cross-sectional area of the medium and the difference in energy height between the inlet and outlet points and inversely proportional to the length of the path. The Law is written as follows:

$$
q=k(A \Delta h) / L
$$

Where; $k$ is the medium permeability coefficient. These equations are often also written in the equation of the hydraulic gradient as:

$$
q=k . i . A
$$

Seepage can be calculated by the equation :

$$
F s=i \cdot \gamma_{w} . V
$$

Fs is Seepage $(\mathrm{kN})$,

$i$ is hidraulik gradient,

$V$ is volume of water $(\mathrm{m} 3)$, $\gamma_{w}$ is water specific gravity $(\mathrm{kN} / \mathrm{m} 3)$.

\subsubsection{Flownet}

A diagram showing several flow lines and equipotential lines is called a flownet. A flow line is a line along which water droplets will move from the upstream to downstream through a permeable soil media. An equipotential line is a line along which the potential height hydraulic pressure? at all points on the line is the same. Permeability of the medium is assumed to be isotropic $(\mathrm{kx}=\mathrm{kz}=\mathrm{k})$

\subsubsection{Effect of Water Pressure on Soil Stability}

Hydrodynamic pressure has a great influence on soil stability. It depends on the direction of flow and can be influenced by the weight of the soil volume.

\subsubsection{The Floating Condition Theory (Quick - condition)}

Hydrodynamic pressure can change the balance/stability? of the soil layer. In a balanced state, the magnitude of the force acting down $\mathrm{W}=\gamma^{\prime}$ is equal to $\mathrm{D}=\gamma \mathrm{w}$.ic or : 


$$
\mathrm{W}-\mathrm{D}=0
$$

With $i_{c}$ the critical hydraulic gradient on the balance of force above. The amount of weight of the submerged soil is :

$$
\begin{aligned}
& W=\gamma^{\prime}=(1-n)\left(G_{s}-1\right) \gamma_{w} \\
& \gamma^{`}=\frac{G_{s}-1}{1+e} \gamma_{w}\left(k N / m^{3}, t / m^{3}\right)
\end{aligned}
$$

Where :

$N$ is porosity

$G_{s}$ is specify gravity

$E$ is void ratio

$\gamma_{w}$ is water unit weight

\subsubsection{Safety Factor for Piping}

If the uplift that occurs in the soil is the same as the ic, the soil will float. This kind of situation can also result in the transportation of fine grains of the soil, causing pipes to occur in the soil. These cavities can undermine the foundation disturbing the stability of the structure. The safety factor water structures against the danger of piping is, according to Harza (1935), as follows:

$$
S F=\frac{i c}{i e}
$$

Where :

$\mathrm{SF}=$ safety factor

$I_{e}=$ the maximum exit gradient, also be determined from the net current and the magnitude equal to :

$$
=C \frac{h}{B}
$$

$I_{c}=\frac{\gamma^{2}}{\gamma_{w}}=\frac{G_{s}-1}{1+e} \rightarrow$ critical hydraulic gradient

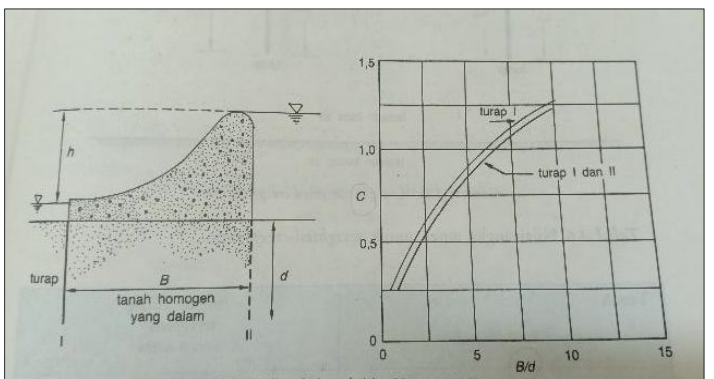

Fig. 2. Harza Method

\section{Results and Discussion}

\subsection{Numerical Analysis}

The acceptable safety factor against piping for a dam is bigger than $3(>3)$.

Calculation example :

For bore hole $05-1$

$$
\begin{aligned}
& i_{c}=\frac{25,890}{10}-1=1,589 \\
& i_{e}=\frac{c * h / B}{k}=\frac{0,2857}{0,023}=12,422 \\
& S F=\frac{1,589}{12,422}=0,127=<3 \rightarrow \text { not safe }(10)
\end{aligned}
$$

\subsection{Numerical Simulation - Finite Element Method}

The most commonly used seepage analysis is a finite element method as it:

1. Can solve complex problems easily from a model.

2. Does not require a change in the dimensions of the dam due to the influence of the physical properties of the materials.

3. Outputs results in the form of equipotential lines and pore pressures at each nodal point.

4. Allows easy variation of soil parameters in the model. The Finite element method solves differential equations, both ordinary differential equations and partial differential equations numerically by dividing complex problems into small parts or the smallest elements so that a simpler solution can be obtained.

\subsection{Stages of Research Study}

The stages of this study consisted of:

1. Secondary data collection for the calculations.

2. Numerical analysis using the finite element method.

3. Calculation of the dam safety factor for piping.

4. Application of results to possible mitigation action.

Table 1. Soil parameters for BK-5, BK-2, and BK-4

\begin{tabular}{|c|c|c|c|c|c|c|c|c|c|}
\hline bore hole & $\begin{array}{c}\text { unsat } \\
(\mathrm{KN} / \mathrm{m} 3)\end{array}$ & $\begin{array}{c}\mathrm{sat} \\
(\mathrm{KN} / \mathrm{m} 3)\end{array}$ & $\begin{array}{c}\mathrm{kx} \\
(\mathrm{m} / \mathrm{dav})\end{array}$ & $\begin{array}{c}\mathrm{ky} \\
(\mathrm{m} / \mathrm{dav})\end{array}$ & $\begin{array}{c}\mathrm{c} \text { (cohesion) } \\
(\mathrm{K} / \mathrm{m} 2)\end{array}$ & $\begin{array}{c}\text { (phi) } \\
(\mathrm{o})\end{array}$ & $\mathrm{Cc}$ & $\mathrm{Cs}$ & $\begin{array}{c}e \\
\text { (void ratio) }\end{array}$ \\
\hline \multirow{3}{*}{ BK - 5 } & 15,887 & 25,890 & 0,023 & 0,023 & 38 & 5,1 & 0,387 & 0,0387 & 1,54 \\
& 15,004 & 23,928 & 0,028 & 0,028 & 37 & 4,8 & 0,621 & 0,0621 & 1,86 \\
& 17,456 & 30,303 & 0,047 & 0,047 & 35 & 4 & 0,414 & 0,0414 & 1,01 \\
\hline \multirow{3}{*}{ BK - 2} & 15,887 & 25,890 & 0,054 & 0,054 & 38 & 5,1 & 0,387 & 0,0387 & 1,54 \\
& 15,004 & 23,928 & 0,010 & 0,010 & 37 & 4,8 & 0,621 & 0,0621 & 1,86 \\
& 17,162 & 29,224 & 0,040 & 0,040 & 25 & 3,3 & 0,567 & 0,0567 & 1,07 \\
\hline \multirow{3}{*}{ BK - 4 } & 16,966 & 29,028 & 0,058 & 0,058 & 27 & 5,1 & 0,459 & 0,0459 & 1,1 \\
& 17,162 & 29,224 & 0,027 & 0,027 & 25 & 3,3 & 0,567 & 0,0567 & 1,07 \\
& 17,456 & 30,303 & 0,044 & 0,044 & 35 & 4 & 0,414 & 0,0414 & 1,01 \\
\hline
\end{tabular}




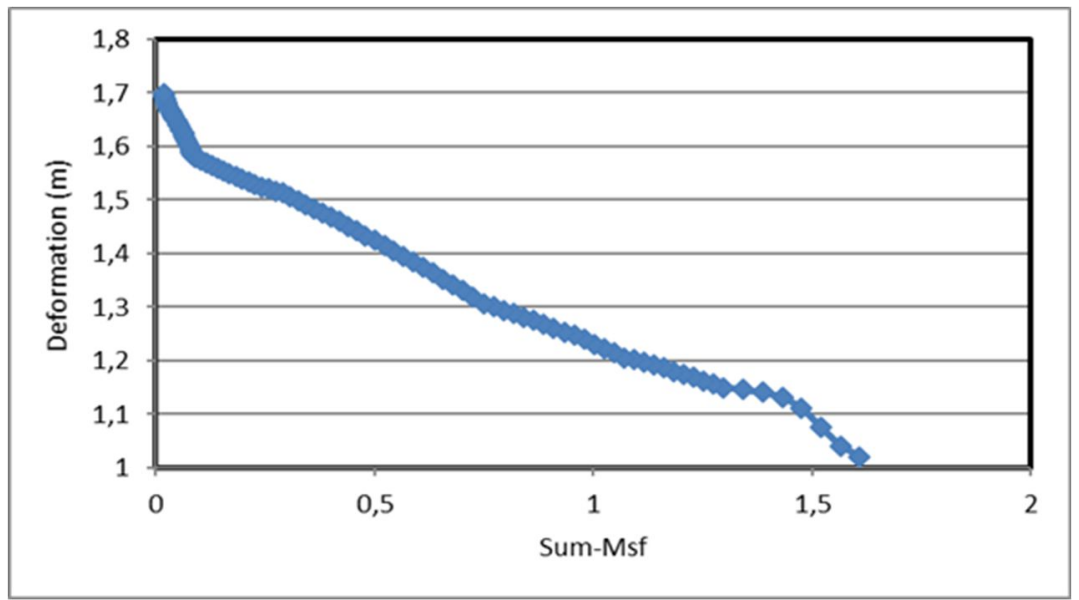

Fig. 3. Graph of Dam Deformation

The largest soil deformation was shown to be under the dam at about $1.7 \mathrm{~m}$

\subsection{Safety Factor of Dam Against Piping}

Table 2. SF calculation for piping

\begin{tabular}{|c|c|c|c|c|c|c|c|c|}
\hline bore hole & $\mathrm{k}(\mathrm{m} / \mathrm{day})$ & $\mathrm{C} \times \mathrm{h} / \mathrm{B}$ & $\mathrm{I} e$ & $\begin{array}{c}\gamma \mathrm{sat} \\
(\mathrm{KN} / \mathrm{m} 3)\end{array}$ & $\gamma \mathrm{w}$ & $\mathrm{I} c$ & $\mathrm{SF}$ & $\mathrm{KET}$ \\
\hline \multirow{3}{*}{$\mathrm{BK}-5$} & 0,023 & 0,2857 & 12,4224 & 25,890 & 10 & 1,5890 & 0,127911 & unsafe \\
& 0,028 & 0,2857 & 10,3520 & 23,928 & 10 & 1,3928 & 0,134547 & unsafe \\
& 0,047 & 0,2857 & 6,1312 & 30,303 & 10 & 2,0303 & 0,331134 & unsafe \\
\hline \multirow{3}{*}{$\mathrm{BK}-2$} & 0,054 & 0,2857 & 5,3405 & 25,890 & 10 & 1,5890 & 0,297532 & unsafe \\
& 0,010 & 0,2857 & 27,4725 & 23,928 & 10 & 1,3928 & 0,050699 & unsafe \\
& 0,040 & 0,2857 & 7,1968 & 29,224 & 10 & 1,9224 & 0,267115 & unsafe \\
\hline \multirow{3}{*}{$\mathrm{BK}-4$} & 0,058 & 0,2857 & 4,9432 & 29,028 & 10 & 1,9028 & 0,384926 & unsafe \\
& 0,027 & 0,2857 & 10,7009 & 29,224 & 10 & 1,9224 & 0,179646 & unsafe \\
& 0,044 & 0,2857 & 6,4935 & 30,303 & 10 & 2,0303 & 0,312659 & unsafe \\
\hline
\end{tabular}

\subsection{Mitigation Efforts}

Dam planning must include Emergency Action Plan Guidelines (RTD) as one of the standards or guidelines in dam security in the event of dam failure. This guideline is published by the Minister of Public Works Regulation No. 72 / PRT / 1997 concerning Dam Safety and Attachment to Director General of Irrigation Decree No. 94 / KPTS / A / 1998 dated 30 July 1998 concerning Guidelines for Preparing Emergency Action Plans.

1. Pre-disaster

Using numerical simulations with the finite element method to determine the seepage value that occurs in the dam. If the value is less than the required safety factor, the potential for dam erosion will be even greater (unsafe). [1,2,3]

Disaster mitigation includes paying attention to safety factors when designing the dam.

2. During a disaster

When a disaster occurs, mitigation efforts include aiming to reduce seepage in the short term and are temporary. Sandbags can be used to block the seepage water flow until a more permanent construction can be built.

3. Post-disaster

Numerical simulations using the finite element method are used to analyze seepage in the planned construction repair varying the parameters of soil and structure so that the safest design can be chosen.

\section{Conclusions}

1 From analysis, the largest soil deformation is under the dam at around $2.1 \mathrm{~m}[6,7]$

2 All piping SF values were smaller than $3(\mathrm{SF}<3)$ meaning the dam is not safe against piping so requires redesign with new structural parameters. The new parameters are simulated again using the finite element method and the safety factor for piping is recalculated. $[8,9]$

3 Pre-disaster mitigation efforts include reducing the potential for seepage can be done during structural planning. Numerical simulation with finite element method can be used as an alternative to the calculation process. By varying the parameters, the 
safest and most efficient design can be chosen for the dam. [10]

\section{References}

1. H. Setyawaty, N. Najib, A. Hidayatillah, UD Sem, (2012)

2. Sukirman,. JTSL, 2, No. 2 (2014).

3. Al-Adili, Aqeel., 2012, 1st int. conf. of water resc, Uni. Of Technology, Iraq-(2012)

4. Khan, Bazid., M. Amin, N. Badshah, JS Tech and Dev of Pakistan (2013)
5. Fattah, Y Mohammed., Salama Al-Labban., Firas A. Salman, IJCIET, 5(8):128-139 (2014)

6. Nanda T. Ferry, Hamdhan, I. Noer, JRR, 2, No. 4, Dec (2016)

7. Setyanto, Z. Ahmad, P.G. Wibawa., JR, 20, No. 20, Aug (2016)

8. A. Yuli, M. Aniek, M. Suwanto, JTP, 3, No. 1, Hlm 51-60, Mei (2012)

9. S. Rivai, J. Anton, KNTS 7 USM, Oct (2012)

10. M. Ari, J.P. Tri, A. Runi, JTP, 7, No. 2, Hlm 193204, Dec (2016) 